"Critical analysis of entrepreneurial spirit, attitudes and perceptions of young South Africans in KwaZulu-Natal province"

\begin{tabular}{ll} 
AUTHORS & Lawrence Mpele Lekhanya \\
\hline ARTICLE INFO & $\begin{array}{l}\text { Lawrence Mpele Lekhanya (2016). Critical analysis of entrepreneurial spirit, } \\
\text { attitudes and perceptions of young South Africans in KwaZulu-Natal province. } \\
\text { Problems and Perspectives in Management, 14(3-1), } 179-184 . \\
\text { doi:10.21511/ppm.14(3-1).2016.04 }\end{array}$ \\
\hline DOI & http://dx.doi.org/10.21511/ppm.14(3-1).2016.04 \\
\hline RELEASED ON & Tuesday, 06 September 2016 \\
\hline JOURNAL & "Problems and Perspectives in Management" \\
\hline FOUNDER & LLC "Consulting Publishing Company "Business Perspectives"
\end{tabular}

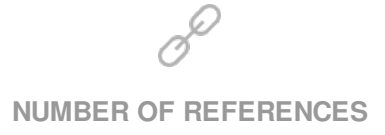

0

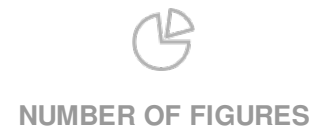

0

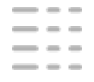

NUMBER OF TABLES

0

(C) The author(s) 2022. This publication is an open access article. 


\title{
Critical analysis of entrepreneurial spirit, attitudes and perceptions of young South Africans in KwaZulu-Natal province
}

\begin{abstract}
Positive entrepreneurial spirit, attitudes and perceptions among the communities, with specific reference to young South Africans in KwaZulu-Natal province, can improve the lives of many young people and alleviate poverty and unemployment challenges in the province. This paper intends to analyze the entrepreneurial spirit, attitudes and perceptions of young South Africans, in addition to which it will also analyze the most critical factors affecting young South Africans when embarking into business. Primary data were collected by means of both qualitative and quantitative methods. Data were collected in eThekweni Municipal areas. The sample consisted of 350 young South Africans between the ages of 18-35, both those who are working, as well as those who are unemployed, with or without tertiary qualifications. Respondents completed a five-point, Likert scale questionnaire, with the assistance of an interviewer. The results disclose that the large number of respondents indicate bank requirements to obtain a loan and financial support as major barriers to starting a business. The findings further indicate start-up capital as another constraint that demoralizes, quelling the entrepreneurial spirit among the young. The results found to be statistical significant at $\left(p=.000^{*}\right)$. Further research should aim to examine youth entrepreneurial training programs and entrepreneurial support skills.
\end{abstract}

Keywords: entrepreneurial, analysis, spirit, attitudes, perceptions, critical, young South Africans.

JEL Classification: M21.

\section{Introduction}

With the rate of youth unemployment in South Africa currently at $48 \%$ (Global Entrepreneurship Monitor, 2012), the greatest challenge in fixing this crisis is the creation of more jobs; this is supported by a review of literature. It has further been established that a number of developed economies would not have advanced, had it not been for the growth of their small business and entrepreneurial sectors (Bawuah, Buame \& Hinson, 2006). The importance of the development of an entrepreneurial spirit among the youth lies in its contribution to the alleviation of poverty, to generate employment opportunities, as well as deal with problems of wrong doing and crime that stem from joblessness in South Africa (Mahadea, Ramroop \& Zewotir, 2011). Even though entrepreneurial development is important for economic development, Herrington, Kew \& Kew (2009) hold that entrepreneurship must be connected to aspects that inspire confidence, a positive opinion of entrepreneurship and the aspiration to take the risk required to start a new business, for it to be seen as a sustainable income-generating activity. The economic potential of all people in South Africa could be unleashed through a culture of entrepreneurship, especially among the youth, for whom options need to be provided that make it possible for them to participate in the economy. Steenekamp, van der Merwe \& Athayde (2011) stress that the passing on of innovative knowledge and skills should be built-in to the basic education goals, should young leaners completing school be expected to play a meaningful

(C) Lawrence Mpele Lekhanya, 2016.

Lawrence Mpele Lekhanya, Durban University of Technology, South Africa. role in economic activity. Included in the entrepreneurial capacity factors are personality traits, learning, experiences, social factors and culture; along with entrepreneurial enhancing factors, for example, information technology development, as well as infrastructure, finance and technical factors. These capacity and enhancing factors are found to be among the main issues influencing the attitude of youth towards entrepreneurship (Dionco-Adetayo, 2006). However, Jacqui, Herrington, Litovsky \& Gale (2013) indicate that several difficulties have been pinpointed by young people across the globe. Among these are access to finance, inadequacy of suitable skills, infrastructure, support structures and mentorship as obstacles for young people to achieve success through entrepreneurship.

\section{Problem statement}

Global Entrepreneurship Monitor (2012) reports that, at $2.3 \%$, South Africa' recognized business rate is the second lowest in the world again, a regular outcome in GEM's South African surveys. The rate is, once more, also more than $5 \%$ below the average for countries that are efficiency-driven (8\%). The report further indicates that the South African youth's early-stage entrepreneurial activity rate, at $7 \%$, is not only the lowest of the 10 sub-Saharan African countries, but also far below the average of $29 \%$ for these 10 countries. Literature indicates that many challenges are faced by young South Africans; however, a particularly dismal scenario for social development and the future of the youth is created, with the likelihood of long-term unemployment after school. With limited research results available regarding the attitude of young South African learners towards entrepreneurship and their future plans, more 
information is, consequently, needed, in order to develop appropriate interventions to increase the employability of learners completing school (Steenekamp, van der Merwe \& Athayde, 2011). Dzisi (2014) supports the premise that, notwithstanding the vital role the youth plays in economic development, little effort has been made to study entrepreneurship from the youth's perspective. This statement is substantiated by limited, if any, detailed research and substantial data on youth entrepreneurship, specifically regarding the main limitations young people are encumbered with, at start-up and when attempting to maintain a business successfully in a developing context.

1.1. Aims: The intention of this paper is to determine the entrepreneurial spirit, perceptions, and attitude of young South Africans in KwaZulu-Natal (KZN) and to identify those factors affecting them.

\subsection{Objectives:}

- to determine the entrepreneurial spirit, perceptions and attitude of young South Africans in KZN;

- to identify factors influencing the entrepreneurial spirit, perceptions, and attitude of young South Africans in KZN.

1.3. Research questions: What are the entrepreneurial spirit, perceptions, and attitude of young South Africans; what are the factors influencing the entrepreneurial spirit, perceptions and attitude of young South Africans; and what can be done to improve the entrepreneurial spirit, perceptions, and attitude of young South Africans?

\section{Literature review}

2.1. The role of young entrepreneurs in economic growth. An entrepreneur who is also a business leader will find ideas and put them into practice by encouraging economic development and growth (Kumar, 2014). Furthermore, Smith (2010) defines entrepreneurship as simply the number of new businesses formed in a given time period. This means that entrepreneurship should, therefore, be incorporated as a foremost cause of economic growth, separate of the other factors. Kew, Herrington, Litovsky \& Gale (2013) maintain that not only does youth entrepreneurship afford an option to create employment for the youth, fostering entrepreneurship among young people, who are more innovative, will encourage the potential to create new forms of independent work. According to Shrivastava \& Shrivastava (2013), entrepreneurship is good for economic growth, given that entrepreneurs create new businesses, which, in turn, create new jobs for people, subsequently, aiding in strengthening competitiveness. The resultant effect is that with the help of technology productivity is increased, thus, playing a critical role in the development of the country, resulting in economic growth. Fatoki and Chindonga (2011) point out that young people's engagement in entrepreneurship helps them to achieve economic independence and reduce their reliance on state welfare. Like any other developing country, when most young people engage in business, the level of unemployment among the youth is minimized (Sindabiwe \& Mbabazi, 2014).

2.2. State of youth entrepreneurship in South Africa. According to Kew, Turton, Herrington \& Christensen (2013), only nine percent of the adult population and only one percent of the youth population is involved in entrepreneurial activity in South Africa. This is very low compared to other countries in Africa and most developing countries. With regards the state of South Africa's entrepreneurship and small business development, when compared with other countries at similar development levels, is generally perceived as that of under-performance (Luiz \& Mariotti, 2011). In so far as being supportive of entrepreneurs, specifically where regulations, policies and access to capital are concerned, the country's financial and operating environment has been found to not offer the needed support. In South Africa, the banking system is the principal source of capital for starting and growing a business, while there are distinctive financial structures that function as this support role in other emerging countries (The entrepreneurial dialogues, 2009). According to Herrington (2013), with reference to perceived opportunities and capabilities, as well as entrepreneurial intentions, South Africa's score was the lowest of 10 sub-Saharan African countries. This is way below countries with much smaller economies than South Africa, including Zambia and Angola. South Africa's lagging entrepreneurial spirit is blamed, among other challenges, on the problem of poor education, especially where maths and science are concerned, by Herrington (2013).

2.3. Entrepreneurial perceptions of young South Africans. On the one hand, a poorly developed entrepreneurial culture has been found, to some extent, to hamper South Africa's capacity to deal with the high unemployment and poverty levels (Burger \& O' Neill, 2004). While, on the other hand, the scarcity of entrepreneurial skills has lowered the rate of youth start-ups and "search effectiveness of potential young entrepreneurs" (Brixiová, Ncube \& Bicaba, 2014).

2.4. Youth entrepreneurship constraints. It is more likely that youth entrepreneurs will have to, as stated by Hutchinson, Guttentag, Chen \& Mo (2012), manage the difficulties associated with access to resources, for example, capital, lower market value, and a narrower range of activities, as well as a lack of access to space, limited or no business experience and a shortage of equipment. Research shows that young 
entrepreneurs face many obstacles in the course of starting-up, as well as during ongoing stages of their business. Of these obstacles, the most vital include not having the right to the use of finance, a negative attitude to entrepreneurship, both socially and culturally, and limited or non-existent management experience (Dzisi, 2014). There are also ethical concerns related to influencing disadvantaged youth to become entrepreneurs, without them being fully aware of the social and economic implications for themselves and their dependents (Pantea, 2014).

\section{Methodology}

A literature review was conducted on the state of youth entrepreneurship in South Africa and utilized to source information, with which to formulate the research questionnaire that mainly consisted of closedended questions.

3.1. Target population. A questionnaire was used to collect primary data from 350 respondents regarding their entrepreneurial spirit, attitudes and perceptions. The study was confined to the KwaZulu-Natal province only, with the province selected for the investigation, as it represents a large percentage of the South African population and is proportionally representative of all racial groups.

3.2. Measuring instrument. The measuring instrument for this study was a questionnaire, with mainly closed-ended questions, which were identified and drawn from the literature. An indication, as to which of the factors that had been identified influence their entrepreneurial spirit and attitude, was required from respondents. The response categories were kept simple for respondents to easily understand. Each question offered five categories to choose from, on average. The main questions are summarized in Table 1:

Table 1. Summary of key questions

\begin{tabular}{|l|l|}
\hline \multicolumn{1}{|c|}{ Research area } & \multicolumn{1}{c|}{ Question } \\
\hline Entrepreneurial spirit & $\begin{array}{l}\text { There is always positive entrepreneurial spirit to have } \\
\text { business. } \\
\text { Response alternative: strongly disagree, disagree, } \\
\text { neutral, agree, strongly agree. }\end{array}$ \\
\hline $\begin{array}{l}\text { Entrepreneurial } \\
\text { attitude }\end{array}$ & $\begin{array}{l}\text { The attitude is very positive towards starting and having } \\
\text { business. } \\
\text { Response alternative: strongly disagree, disagree, } \\
\text { neutral, agree, strongly agree. }\end{array}$ \\
\hline $\begin{array}{l}\text { Entrepreneurial } \\
\text { perceptions }\end{array}$ & $\begin{array}{l}\text { There are always positive perceptions with regard to } \\
\text { owning business. } \\
\text { Response alternative: strongly disagree, disagree, } \\
\text { neutral, agree, strongly agree. }\end{array}$ \\
\hline Limiting factors & $\begin{array}{l}\text { There are many limiting factors to start and own } \\
\text { business. } \\
\text { Response alternative: strongly disagree, disagree, } \\
\text { neutral, agree, strongly agree. }\end{array}$ \\
\hline Contributing factors & $\begin{array}{l}\text { The following are contributing factors to the } \\
\text { entrepreneurial spirit: } \\
\text { Response altermative: Financial support, Red tape, } \\
\text { bank requirements, competition, weak domestic } \\
\text { demand, lack of business skills and mentorship. }\end{array}$ \\
\hline
\end{tabular}

3.3. Data collection. A quantitative survey method was utilized to collect primary data. In order to obtain the necessary information, a questionnaire was designed and pre-tested. The data were collected through a closed-ended, self-administered questionnaire, in which a number of alternative answers were provided for respondents to choose from. Improvement of the response rate and validity was encouraged with instructions provided throughout the questionnaire, and interviewers on hand to, where necessary, assist with any uncertainties. Having all questionnaires pre-coded avoided inconsistencies in the coding of the closed-ended questions.

3.4. Analysis of research data. Once questionnaires had been examined for completion and missing information, data were captured by means of a statistical package SPSS, version 22.0. While frequencies were involved in the first analysis and also used to verify the coding of data, descriptive statistics were made use of in describing and comparing the data collected.

3.5. Validity and reliability. By pre-testing the questionnaire with a small sample similar to the population, the questionnaire was evaluated by the researcher, with the assistance of statistical experts, in order to establish content and construct for this study; there were no significant changes required. The results of the Cronbach's coefficient Alpha test, to determine a coefficient of 0.75 , show that the study's reliability was acceptable at $.929^{*}$ Cronbach's Alpha.

\section{Findings}

The result, as indicated in Figure 1, illustrates that 11 ( 3 percent) and 28 ( 8 percent) of the respondents disagreed with the statement that there is always a positive entrepreneurial spirit among young South Africans, while 25 (7 percent) are neutral with regard to the statement. However, a large proportion of 230 (66 percent) and 56 (16 percent) respondents agreed with the statement. A Chi-square goodness of fit test was conducted on the entrepreneurial spirit of young South Africans, showing this to be significant $(p=.000 ;$ mean $=3.8343 ;$ std $=0.89952)$.

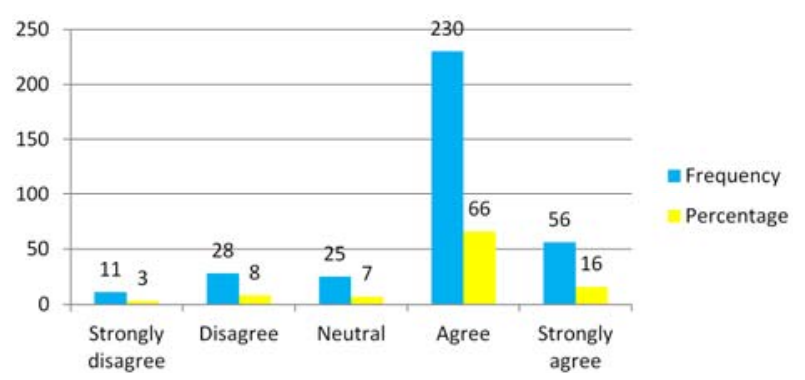

Fig. 1. Entrepreneurial spirit of the respondents

As shown in Figure 2, 21 (6 percent) indicated neutral regarding the statement that the attitude is very 
positive towards starting and having a business. Less than half of the respondents, seven ( 2 percent) and 20 (6 percent), disagreed with the statement, while the majority of the respondents, 215 (61 percent) and 87 (25 percent), agreed with the statement. A Chi-square goodness of fit test was conducted on the entrepreneurial attitude of young South Africans; with results showing this to be significant $(p=.000$; mean $=4.580 ;$ std $=0.77166$ ).

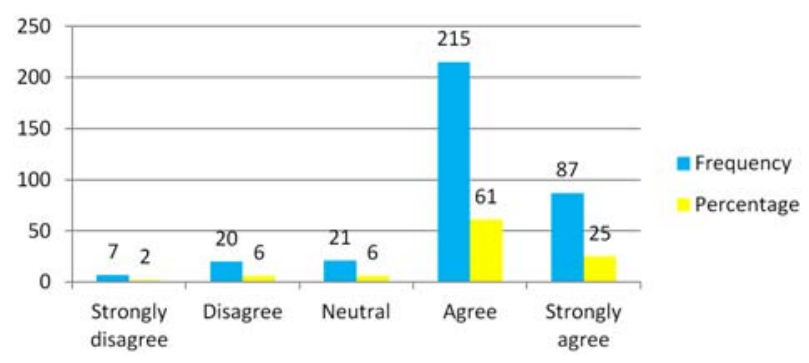

Fig. 2. Entrepreneurial attitude of the respondents

The results shown in Figure 3 reveal that five (1 percent) and nine (3 percent) of the respondents disagreed that there are always positive perceptions with regard to owning a business. While a total of 23 (7 percent) indicated neutral, a large number of the respondents, 200 (57 percent) and 113 (32 percent), agreed with the statement. A Chi-square goodness of fit test showed this finding to be statistically significant $(p=.000 ;$ mean $=4.1629 ;$ std $=0.77148)$.

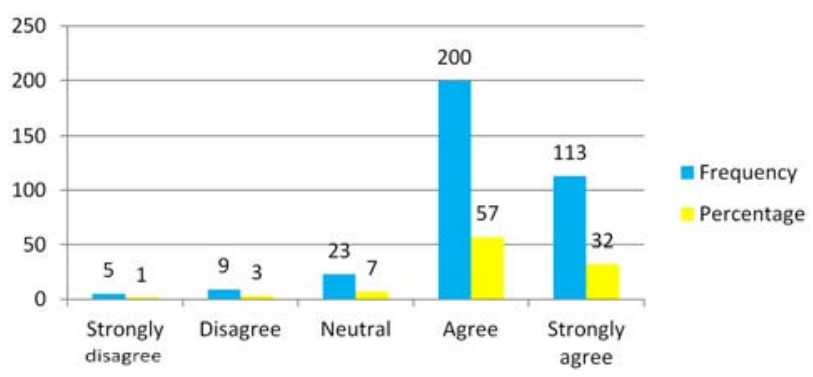

Fig. 3. Entrepreneurial perceptions of the respondents

The results, as shown in Figure 4, indicate that eight (2 percent) and 11 (3 percent) of the respondents disagreed that there are many limiting factors to starting and owning a business. While 27 ( 8 percent) indicated neutral, 210 (60 percent) and 94 ( 27 percent) agreed. This finding is shown to be statistically significant by a Chi-square goodness of fit test $(p=.000 ;$ mean $=4.0600 ;$ std $=0.82187)$.

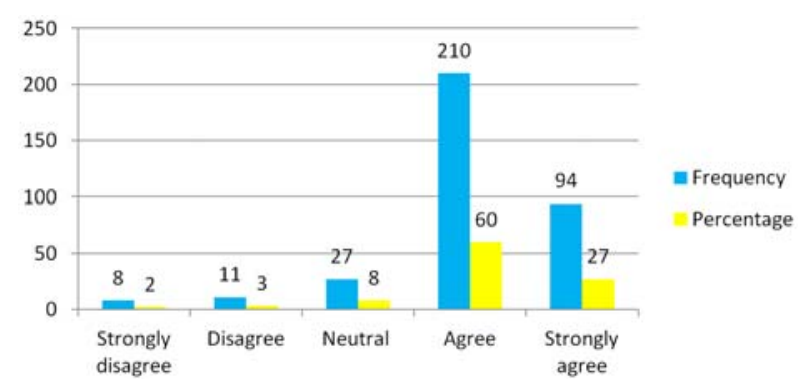

Fig. 4. Respondents' statements on youth entrepreneurial limiting factors
Figure 5 shows that financial support was stated by 110 (31 percent) and bank requirements by 123 (35 percent), followed by 58 (17 percent) indicating red tape as the most frequently-mentioned problems faced by respondents. This makes sense, when the respondents age and that some of them have not worked before are taken into account. A very small number of the respondents mentioned competition, weak domestic demand and lack of business skills and mentorship as problems. A Chi-square goodness of fit test was conducted on the entrepreneurial spirit of young South Africans, which showed this to be significant $(p=.000$; mean $=2.5829 ;$ std $=1.47675)$.



Fig. 5. Contributing factors to the South African Youth entrepreneurship

4.1. Limitations. This study did not include youth from other provinces in South Africa, as it was confined only to eThekwini municipal metropolitan areas in the province of KZN. Therefore, these results should be generalized with care. Additional research should be undertaken to include more young people from other provinces, specifically with regard to the complexity of South African geographical profiles.

4.2. Research implications. The survey included both theory and practical issues with regard to entrepreneurial spirit, attitudes and perceptions of young South Africans.

4.3. Implications for entrepreneurial, spirit, attitudes and perceptions of young South Africans theories. The development of new concepts and theories in field entrepreneurship should be priority for developing countries, including South Africa. A better understanding of entrepreneurship growth strategy theories must be clearly defined, with specific theories regarding youth entrepreneurial development and growth. The South African government and community at large must understand the challenges faced by and limiting young people to start their own businesses and what needs to be done. The practical theories for entrepreneurship activities from home business basics and school entrepreneurship theories, to business sector theories, must link and build on the establishment of entrepreneurial growth. 
4.4. Implications for entrepreneurial, spirit, attitudes and perceptions of young South Africans practice. The findings of this study reveal that a large number of respondents do not have financial support, as they do not meet bank requirements to obtain loans, while, at the same time, when trying to get business operating licences, red tape was indicated as affecting their spirit and attitudes to start businesses. Because of this lack of start-up capital, young South Africans find it difficult to start businesses and they might also lose interest in entering the business sector. The practical implications of this study will, therefore, benefit the South African government and all relevant stakeholders when working on new policies for the developmental growth of youth entrepreneurship in South Africa.

\section{Conclusions}

Based on the findings of the study, it has been established that lack of financial support, difficult of access to finance, and red tape are significant problems for youth entrepreneurship in South Africa. This study concludes that there is positive entrepreneurial spirit, attitude and perceptions among young South Africans, with specific reference to the KZN province. Moreover, it is imperative that the South African government understands the entrepreneurial needs of young South Africans and other factors limiting their growth. Government should also fast-track the process of issuing business licences, as this could have a major impact on encouraging young South Africans to enter into business. Poor quality education and training, and lack of entrepreneurial education systems in South African result in lack of wiliness, positive attitudes and business spirit among the youth.

\section{Recommendations}

The findings of the study suggest that red tape, when seeking to obtain a business licence, is an issue of concern among young South Africans. Therefore, it is recommended that government should introduce business consulting offices in all municipal districts, as well as in each provincial municipality that will deal with all issues relating to business development.

\section{References}

1. Bawuah, K., Buame, S. \& Hinson, R. (2006). Reflections on entrepreneurship education in African tertiary institutions. Acta Commercii.

2. Brixiová, Z., Ncube, M. \& Bicaba, Z. (2014). Skills and Youth Entrepreneurship in Africa: Analysis with Evidence from Swaziland. Available at: http://www.afdb.org/fileadmin/uploads/afdb/Documents/Publications/Working_Paper_204__Skills_and_Youth_Entrepreneurship_in_Africa-_Analysis_with_Evidence_from_Swaziland.pdf.

3. Burger, L. \& O'Neill, C. (2004). Perceptions of Entrepreneurship as a Career Option in South Africa: An Exploratory Study among Grade 12 Learners, SAJEMS, 7 (2).

4. Dionco-Adetayo, E.A. (2006). Factors Influencing Attitude of Youth towards Entrepreneurship, International Journal of Adolescence and Youth, 13, pp. 127-145.

5. Dzisi, S. (2014). Youth entrepreneurship: investigating obstacles to youth enterprise creation and development, International Journal of Economics, Commerce and Management, 2 (7).

6. Fatoki, O. and Chindonga, L. (2011). An investigation into the obstacles to youth entrepreneurship in South Africa.

7. Herrington, M. (2013). South African entrepreneurship falls to new low, lagging behind the rest of Africa. Available at: http://www.howwemadeitinafrica.com/south-african-entrepreneurship-falls-to-new-low-laggingbehind-the-rest-of-africa/25975/. Accessed on 31/12/2014.

8. Herrington, M., Kew, J. \& Kew, P. (2009). Tracking entrepreneurship in South Africa: A GEM perspective. Available at: http://www.gsb.uct.ac.za/files/Gembook2009.pdf. Accessed on 29/12/2014.

9. Hutchinson, J., Guttentag, M., Chen, V. \& Mo, K. (2012). Youth Entrepreneurship in Serbia: Constraints and Opportunities. Available at: http://www.lokalnirazvoj.rs/upload/YouthEmployment/SrAttachment/201403/ Youth_Entrepreneurship_In_Serbia_GW_Capstone.pdf. Accessed on 02/01/2015.

10. Global Entrepreneurship Monitor (GEM). (2012). Reports - GEM Global Entrepreneurship Monitor. Available at: http://www.gemconsortium.org/repor.

11. Jacqui, K., Herrington, M., Litovsky, Y. \& Gale, H. (2013). Generation Entrepreneur? The state of global youth entrepreneurship. Available at: http://www.gemconsortium.org/docs/download/2835. Accessed on 30/12/2014.

12. Kew, P., Turton, N., Herrington, M. \& Christensen, J.D. (2013). The state of youth entrepreneurship in the Free State: A baseline study of entrepreneurial intentions and activity amongst young men and women. http://apyouthnet.ilo.org/resources/the-state-of-youth-entrepreneurship-in-the-free-state/at_download/file1. Accessed on $31 / 12 / 2014$.

13. Kumar, C. (2014). What is the Role of an Entrepreneur in Economic Development? Available at: http://www.preservearticles.com/201101143326/role-of-an-entrepreneur-in-economic-development.html. Accessed on 30/12/2014.

14. Luiz, J. \& Mariotti, M. (2011). Entrepreneurship in an emerging and culturally diverse economy: a South African survey of perceptions. Available at: http://sajems.org/index.php/sajems/article/view/30/33. Accessed on 31/12/2014.

15. Mahadea, D., Ramroop, S. \& Zewotir, T. (2011). Assessing entrepreneurship perceptions of high school learners in Pietermaritzburg, Kwazulu-Natal, South African Journal of Economic and Management Sciences, 14 (1). 
16. Sindabiwe, P. Mbabazi, D. (2014). Triad Problematic of Youth Entrepreneurship: Voices from University Students, 1 (6), p. 463.

17. Steenekamp, A.G., van der Merwe, S.P. \& Athayde, R. (2011). An investigation into youth entrepreneurship in selected South African secondary schools: An exploratory study, South African Business Review, 15 (3), p. 47.

18. Shrivastava, S. \& Shrivastava, R. (2013). Role of Entrepreneurship in Economic Development, International Journal of Management and Social Sciences Research (IJMSSR), 2 (2).

19. Smith, D. (2010). The Role of Entrepreneurship in Economic Growth. Undergraduate economic review, 6 (1), p. 2.

20. The entrepreneurial dialogues: state of entrepreneurship in South African. (2009). Available at: http://www.gibs.co.za/SiteResources/documents/The\%20Entrepreneurial\%20Dialogues\%20-\%20State\%20of\%20 Entrepreneurship\%20in\%20South\%20Africa.pdf. Accessed on 31/12/2014.

21. Pantea, M. (2014). EU - CoE youth partnership policy sheet: Youth entrepreneurship. Available at: http://pjpeu.coe.int/documents/1017981/1668235/Entrepreneurship-2014.pdf/ed4968a3-e515-4d97-b9a6-30fbbba1857f. Accessed on 03/01/2014. 